\title{
Pediatric Idiopathic Intracranial Hypertension (Pseudotumor Cerebri)
}

\author{
Melissa W. Ko ${ }^{a}$ Grant T. Liu ${ }^{b}$ \\ ${ }^{a}$ Neuro-Ophthalmology Services of the State University of New York at Upstate Medical University, Syracuse, N.Y., \\ and ${ }^{b}$ Children's Hospital of Philadelphia, Hospital of the University of Pennsylvania, and the Scheie Eye Institute, \\ University of Pennsylvania School of Medicine, Philadelphia, Pa., USA
}

\section{Key Words}

Pediatric pseudotumor cerebri • Pediatric idiopathic intracranial hypertension • Papilledema

\begin{abstract}
Idiopathic intracranial hypertension $(\mathrm{IIH})$, or pseudotumor cerebri, is a condition of elevated intracranial pressure in the absence of clinical, laboratory or radiological evidence of an intracranial space occupying lesion that can occur in the pediatric population. While $\mathrm{IIH}$ is more commonly recognized as a disorder of adults, it affects children of all ages and can have distinctive characteristics when presenting in the prepubertal age group. This review discusses the demographics, clinical presentation, diagnosis, neuroimaging, and management of pediatric IIH. Common etiologies of IIH in children, with particular focus on endocrine abnormalities, are highlighted.

Copyright $\odot 2010$ S. Karger AG, Basel
\end{abstract}

\section{Introduction}

Idiopathic intracranial hypertension (IIH), or pseudotumor cerebri, is a disorder of elevated intracranial pressure (ICP) without any evidence of infection, vascular abnormality, space occupying lesion, hydrocephalus or

\section{KARGER}

Fax +4161306 1234

E-Mail karger@karger.ch

www.karger.com
C) 2010 S. Karger AG, Basel

$1663-2818 / 10 / 0746-0381 \$ 26.00 / 0$

Accessible online at:

www.karger.com/hrp alteration of consciousness [1]. While IIH is characteristically diagnosed in obese women of reproductive age [2, $3]$, it is well recognized in children [4-6].

\section{Demographics and Diagnostic Criteria}

IIH can occur at any age in childhood, although $\mathrm{IIH}$ in infants is uncommon [7] and in neonates is exceedingly rare. The incidence of IIH in the general population is 1 of 100,000 [8] and in pediatric IIH there is an increasing incidence among adolescents (12-15 years) as compared to young children (2-12 years) [8]. One study reported that $60 \%$ of children who develop the disorder are over 10 years of age [4]. There is also a growing sentiment that IIH is different in younger than in older children [9], in that younger patients do not demonstrate a propensity towards obesity or a particular sex, and that the developmental milestone of puberty separates the younger and older groups [10]. Since the onset of puberty is an important milestone in IIH and the age of pubertal onset is variable, standard criteria based on secondary sexual characteristics rather than age-specific criteria should be used $[11,12]$. Previously, the Modified Dandy criteria for diagnosis of IIH in adults (table 1) were utilized for the diagnosis of pediatric IIH. Because IIH in young children appears to be different compared to adolescents and adults, 
Table 1. Modified Dandy criteria for diagnosis of IIH $[85,86]$

1 Signs and symptoms of increased intracranial pressure

2 No localizing findings on neurological examination

3 Normal MRI/CT brain scans with no evidence of central venous sinus thrombosis

4 Increased intracranial pressure over $250 \mathrm{~mm} \mathrm{H}_{2} \mathrm{O}$ and normal cerebrospinal fluid composition

5 No other identified cause of intracranial hypertension

Table 2. Proposed diagnostic criteria for prepubertal IIH (modified from $[13,85,86])$

1 If symptoms or signs present, they may only reflect those of generalized intracranial hypertension or papilledema; normal mental status

2 Documented elevated intracranial pressure (age appropriate) measured in the lateral decubitus position; neonates: $>76 \mathrm{~mm}$ $\mathrm{H}_{2} \mathrm{O}$, age 1-18 years: $>280 \mathrm{~mm} \mathrm{H}_{2} \mathrm{O}$

3 Normal CSF composition except in neonates who may have up to $19 \mathrm{WBC} / \mathrm{mm}^{3}$ if $0-28$ days and up to $9 \mathrm{WBC} / \mathrm{mm}^{3}$ if between 29 and 56 days old; the protein may be as high as $150 \mathrm{mg} / \mathrm{dl}$

4 No evidence of hydrocephalus, mass, structural, or vascular lesion on MRI, with and without contrast, and MR venography; narrowing of the transverse sinuses is allowed

5 Cranial nerve palsies allowed if there is of no other identifiable etiology and improve with reduction in cerebrospinal fluid pressure or resolution of other signs and symptoms of intracranial hypertension

6 No other identified cause of intracranial hypertension

Rangwala and Liu [13] proposed new diagnostic criteria for IIH in prepubertal children. In the setting of newly published reference ranges for CSF in children [14], we have modified the proposed diagnostic criteria for pediatric IIH (table 2).

\section{Risk Factors}

\section{Obesity}

In adults, there is an established association between obesity and IIH [15]. In contrast, previous studies indicated only $30 \%$ of children with IIH were overweight [4, 16], suggesting a weak association between pediatric IIH and obesity $[4,16]$. Balcer et al. [17] utilized rigorous methodologies and standard definitions of obesity in children with IIH and examined age trends. Forty pediatric IIH patients were studied and $43 \%$ of patients aged $3-11$ years were obese, whereas $81 \%$ of those in the 12 - to 14 -year age group and $91 \%$ of those in the 15 - to 17 -year age group met the criteria for obesity. This study established that older children with IIH were more likely to be obese than younger children [17].

\section{Sex}

Recent studies have shown that in younger children with IIH, nearly half are males, but in the older age group, the vast majority of patients are female [4]. Balcer et al. [17] noted that $50 \%$ of patients aged 3-11 years were female, whereas $88 \%$ of those in the 12 - to 14 -year age group and $100 \%$ of those in the 15- to 17 -year age group were female.

These recent findings which associate obesity and female gender with IIH in older children suggest that in teenagers, risk factors for developing IIH might be similar to those in adults. Younger children with IIH are less likely to be obese or female, and it is possible that IIH in this younger age group has a different mechanism.

\section{Clinical Presentation}

\section{Symptoms}

While headache, nausea, and vomiting are classic symptoms of IIH, patients may also complain of blurred vision, double vision due to cranial nerve palsies, and stiff neck $[4,18]$. Children can describe visual symptoms including transient visual loss, photophobia, and 'shimmering lights with colored centers' [19]. Patients with IIH have normal levels of consciousness and functioning [19].

Headache is the main complaint among children with IIH and has been documented in $62-91 \%$ of cases $[4,18$, 20]. There are also reports of IIH without headache symptoms [21,22], either because the child is too young to articulate [6] or because headaches are absent [23]. The reason for lack of headache despite increased ICP is unknown. Children with IIH but without headaches, tend to have more neurological signs and vision loss at presentation and a poorer prognosis [20]. The headaches may be a warning sign before vision loss occurs [20], and aggressive reduction of ICP and treatment of papilledema is critical.

Asymptomatic IIH, diagnosed when papilledema is incidentally noted during a routine physical exam, has 

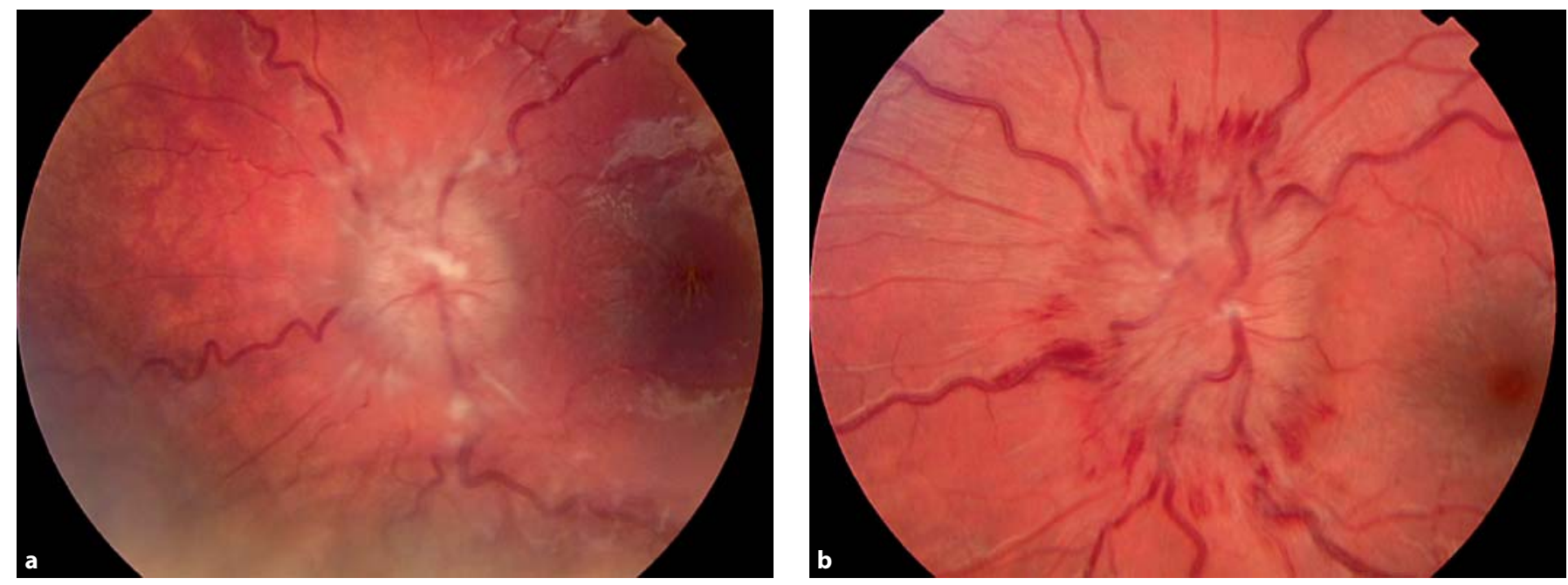

Fig. 1. Two examples of papilledema (optic disc swelling due to elevated intracranial pressure). a The optic nerve is swollen with elevation of the entire nerve head, obscuration of segments of major blood vessels leaving the disc, and increased diameter of the nerve head. b There is elevation of the entire optic nerve head, with obscuration of all borders and multiple peripapillary 'splinter' hemorrhages.

become a recognized entity in younger children $[9,22-$ 26]. These children are asymptomatic and apart from headache management, they receive the same treatment as those with symptoms.

\section{Signs}

Papilledema, ranging from mild blurring of the disc margins to gross disc swelling with hemorrhages and exudates, has been regarded as a hallmark finding of IIH (fig. 1). The disc edema is generally bilateral, but it can be asymmetric or unilateral. Papilledema in children resolves after 3-6 months of medical treatment, but in some cases last for several additional months. In infants with open sutures, papilledema may be absent [22, 26, 27]. In patients without papilledema, there is generally no threat of vision loss and treatment is primarily symptomatic headache management.

Vision loss in pediatric IIH is usually mild to moderate and reversible, but in rare cases it can be devastating and permanent [4]. At presentation, visual acuity loss is reported in 6 to $20 \%$ of children $[4,10,18,21,26]$, while visual field loss occurs in up to $91 \%$ of cases $[4,10,21,22]$. This indicates the importance of serial visual fields, even when visual acuity is within normal range.

Palsies of cranial nerves III [22, 26], IV [18, 22, 28], VI $[4,18,22]$, VII $[4,18,29]$, IX [26], and XII [26] have been seen in children, with the sixth nerve most commonly involved. Reversal of the cranial nerve palsy with ICP lowering is required to associate the palsy with IIH. While the mechanism causing these abnormalities is unclear, there is likely an element of nerve or brainstem traction with increased ICP [30, 31].

\section{Pathogenesis}

The pathogenesis of IIH is unknown. Although brain edema, increased cerebral blood volume, and increased CSF secretion have been postulated as IIH mechanisms $[19,24]$, most attention has been focused on increased venous sinus pressure and decreased CSF absorption. Decreased CSF absorption by arachnoid villi has been demonstrated by radioisotope cisternography, although it is unclear whether it is secondary to compression of the arachnoid villi or by elevated ICP itself [32]. Some have suggested that elevated intracranial venous pressure is a universal mechanism of IIH in adults and children [33]. Elevated venous pressure may increase resistance to CSF absorption, subsequently increasing cerebrospinal pressure. Others disagree, suggesting that because venous sinus stenoses reverse with correction of elevated pressure, elevated venous pressure could be an effect, rather than a cause, of ICP [34-36]. Unfortunately, most of the studies regarding IIH pathogenesis were performed in adults; similar studies in children have not been done. 


\section{Etiology}

While secondary causes for IIH are less commonly identified in adults, in $53-77 \%$ of pediatric cases there is an identifiable underlying condition $[16,26]$. Reported associated conditions include endocrine abnormalities, medications (nalidixic acid, tetracyclines, nitrofurantoin, chemotherapies), viral infections (varicella, measles), nutritional etiologies (vitamin A toxicity, vitamin A or D deficiencies), or systemic conditions (Miller-Fisher syndrome, acute lymphocytic leukemia, Turner syndrome, galactosemia, galactokinase deficiency) [6]. Here we elaborate on IIH etiologies of endocrinological significance.

\section{Endocrine Conditions}

\section{Thyroid Disease}

Cases of pediatric IIH following thyroxine replacement therapy in juvenile hypothyroidism have been described [37-39]. In the majority of these cases, IIH occurred after increasing the dose of thyroxine secondary to persistently elevated thyroid stimulating hormone levels. It has been hypothesized that rapid correction of hypothyroidism with thyroxine, a major regulator of sodium transport, may result in altered CSF dynamics. Additionally, a child with hypothyroidism who developed IIH prior to thyroxine treatment has been reported [30], but given that she was female, obese, and pubertal, it cannot be confirmed that hypothyroidism and IIH were associated. There is also a report of a child with concurrent new diagnoses of Graves' disease and IIH who had resolution of IIH in the setting of thyroid suppressive therapy [40].

\section{Adrenal Corticosteroids}

Corticosteroid withdrawal in children with inflammatory bowel disease (IBD) leading to IIH has been described. In one study, an adolescent with IBD developed IIH during corticosteroid withdrawal after chronic steroid treatment of his gastrointestinal condition [41]. In another, 3 cases of IIH subsequent to treatment with budesonide, a new-generation potent steroid, for Crohn's disease in children were published [42]. All 3 patients had previously been treated with prednisone, experienced symptom resolution with withdrawal of budesonide, and were successfully treated with prednisone later. It is difficult to establish a definite causal relationship between budesonide and $\mathrm{IIH}$, because confounding factors such as hypervitaminosis and iron deficiency anemia were also present in one of the reported cases.

\section{Addison Disease}

While earlier reports suggested an association between papilledema and Addison disease, these cases were limited by the lack of CSF results or the presence of medical conditions that may contribute to IIH. Recently reported cases of Addison disease have met diagnostic criteria for both Addison disease and IIH, and glucocorticoid and mineralocorticoid replacement resulted in resolution of symptoms $[43,44]$, with one patient requiring additional treatment with acetazolamide [44]. Future studies need to further investigate the pathophysiological mechanism leading to IIH as it is possible elevated levels of serum vasopressin may mediate an increase in brain volume and elevated pressures.

\section{Growth Hormone}

Since 1993, there have been multiple cases of IIH in children treated with recombinant (biosynthetic) human growth hormone (GH) [45-47]. In a large analysis, the prevalence of IIH in the GH-treated population was approximately one hundred times greater than in the normal population [46]. An increased occurrence of IIH after insulin growth factor 1 (IGF-1) therapy has also been reported [48]. Factors such as obesity, Turner syndrome, chronic renal failure, Prader-Willi syndrome, and delayed puberty may increase the risk of developing IIH in this setting [49]. One study cited 15 patients with renal insufficiency that developed IIH subsequent to GH treatment [50]. These patients were concurrently being treated with other medications that have been associated with IIH, but IIH developed shortly after beginning GH therapy. A proposed mechanism is that $\mathrm{GH}$ passes the bloodbrain barrier, acting locally to increase IGF-1 levels, which increases CSF production from the choroid plexus [51]. It appears aggressive $\mathrm{GH}$ dosing may increase the risk of developing IIH; thus, starting hormone therapy at the lowest recommended dose, with prudent gradual titration has been advised [52]. Caution must be applied when diagnosing papilledema in a patient with GH deficiency, as congenital disk anomalies may be seen in children with hypopituitarism [53].

When IIH is due to GH treatment, stopping replacement hormone therapy is often sufficient for symptom resolution. Other causes of IIH should still be excluded with neuroimaging and CSF examination. Headaches and vision loss can be treated with acetazolamide. Following IIH resolution, GH can be restarted, but with a slower dose escalation and a smaller standing dose. These measures should prevent recurrence. 
Other

Levonorgestrel implants [54] and desmospressin nasal spray [55] have been reported in pediatric IIH, but the mechanism in each case was unclear.

\section{Clinical Evaluation}

\section{History}

The diagnosis of IIH in children is one of exclusion, as central nervous system neoplasms may present with similar symptoms [56-59]. Nonthrobbing, intermittent headaches that occur upon awakening [57], behavior changes, seizures, and focal neurologic deficits are more likely seen in children with brain neoplasms as compared to those with IIH $[56,58]$. Patients and parents should be asked whether the child has (1) any recent weight gain, (2) taken medications associated with IIH (tetracycline, chronic steroids recently tapered, synthetic GH), or (3) has an underlying medical condition associated with IIH. Development of secondary sexual characteristics should also be recorded. The child should be asked whether he or she has visual symptoms, headache, nausea or vomiting, neck or back pain, or any other neurological complaints.

\section{Examination}

Children with suspected IIH should have a careful neurologic and ophthalmologic examination, performed by a neuro-ophthalmologist detailing visual acuity, color vision, pupillary examination, ocular motility, visual fields and dilated ophthalmoscopy. If a neuro-ophthalmologist is not available, an alternative would be a pediatric ophthalmologist working in conjunction with a pediatric neurologist.

\section{Neuroimaging}

Normal neuroimaging studies are mandatory before diagnosing pediatric IIH and performing a lumbar puncture. Since conditions with meningeal infiltration or cerebral venous sinus thrombosis (CVST) can mimic pediatric IIH and may be missed by CT, MRI of the brain with and without gadolinium for detecting meningeal or intraparenchymal lesions and MR venography (MRV) are the studies of choice for diagnosis of CVST [60]. CT venography (CTV) has been reported to be equivalent to MRV in the diagnosis of CVST in adult patients [61]; however, the concern of radiation exposure via CT must be weighed against the need for sedation in a longer MRI study.

Pediatric Idiopathic Intracranial Hypertension

\section{Lumbar Puncture}

After normal neuroimaging, a lumbar puncture is critical to measure the CSF opening pressure and to exclude meningitis. We recommend a lumbar puncture be performed in the lateral decubitus position with the legs flexed, using mild sedation when necessary, and measuring the opening pressure with a standard manometer. Based on the first prospective study assessing the CSF opening pressure reference ranges in 165 children, we recommend using $280 \mathrm{~mm} \mathrm{H}_{2} \mathrm{O}$ as the normal opening pressure for patients between 1 and 18 years of age [14]. Cerebrospinal fluid reference ranges in neonates are different compared to values in young children. In normal neonates, a value above $76 \mathrm{~mm} \mathrm{H}_{2} \mathrm{O}$ is considered an elevated CSF opening pressure [62]. While for infants aged $\leq 28$ days, a cell count above $19 / \mu$ lis considered elevated, the value for infants ages $29-56$ days is greater than $9 / \mu \mathrm{l}$ [63]. CSF protein can be relatively elevated in neonates (up to $150 \mathrm{mg} / \mathrm{dl}$ ), but will decline to normal levels (15-45 $\mathrm{mg} / \mathrm{dl}$ ) after the first 6 months of life [64].

\section{Treatment}

Currently, there is an ongoing randomized, controlled, double blind prospective study of treatment of IIH in adults, but no data exist in children. Therefore, treatment is empirically dictated by the level of vision loss and severity of headache. Toxic, metabolic, and nutritional causes must be promptly addressed, and weight loss must be encouraged in children who are overweight. We recommend a weight loss of $10 \%$ less than the child's weight at diagnosis [65]. Repeat lumbar punctures are discouraged by most experts because they are painful, poorly tolerated in young children, who often require sedation, and have short-lived effects as the drained spinal fluid is replenished in a day [19].

Most cases of pediatric IIH respond to medical management; thus, surgical management is typically reserved only for those who fail medication. In rare instances, patients may respond to one spinal tap with resolution in papilledema without the need for additional therapy.

\section{Medical Management}

Acetazolamide or furosemide are commonly used in the medical management of pediatric IIH [9]. Acetazolamide, a carbonic anhydrase inhibitor, is thought to reduce the rate of CSF production, and is generally the firstline treatment. We orally dose at $15 \mathrm{mg} / \mathrm{kg} /$ day in $2-3$ divided doses, until headache, disc swelling, and visual 
field abnormalities resolve - typically in 3-9 months. Common dose-related side effects include GI upset, paresthesias involving the lips, fingers, and toes, anorexia, and electrolyte imbalance (metabolic acidosis). Kidney stones are rare and aplastic anemia is exceedingly uncommon. We do not monitor electrolytes as children are usually asymptomatic from the acidosis. When the side effects become intolerable, the dose is lowered or acetazolamide is replaced with furosemide $(0.3-0.6 \mathrm{mg} / \mathrm{kg} /$ day). There are reports of combining acetazolamide with furosemide to produce additive results and reduce pressure more effectively than with just acetazolamide alone [66].

Topiramate $(1.5-3.0 \mathrm{mg} / \mathrm{kg} /$ day in two divided doses, and no more than $200 \mathrm{mg} /$ day) may be used as a secondline agent, particularly when the child is obese. Topiramate, an antiepileptic medication, has secondary carbonic anhydrase activity. Topiramate use in IIH is relatively new [67] and has the added benefit of appetite suppression and weight loss in many patients. It is an excellent medication for chronic daily headache and it has been used safely for years in children with epilepsy. The dosage should be increased slowly over weeks ( $25 \mathrm{mg} /$ week) to reduce the risk of cognitive side effects, which are more common with rapid dose escalations and at doses $\geq 200$ $\mathrm{mg} /$ day [68]. If topiramate is not tolerated, zonisamide, also with carbonic anhydrase activity and appetite suppression, may be used.

In situations of acute, severe visual loss, the combination of oral or IV acetazolamide and IV methylprednisolone $15 \mathrm{mg} / \mathrm{kg}$ can be used when surgery is not immediately available [69]. The use of chronic steroids, however, should be avoided.

\section{Headache Management}

Headaches usually resolve with reduction of ICP. If needed, additional pain management with conventional prophylactic and symptomatic headache medications is helpful [70]. Nortriptyline and sodium valproate should be judiciously selected because of the side effect of weight gain, which should be avoided in IIH patients [71]. For this reason, topiramate and zonisamide may be more preferable for headache prophylaxis in IIH. Abortive medications for headache that can be used include acetaminophen or nonsteroidal anti-inflammatory agents. Migraine-specific triptan drugs are not typically used in patients with IIH.

Even with aggressive medical management, headaches may persist in some children [21]. While many of these headaches may result from analgesic overuse, in most instances, the reasons for persistent headaches are unclear. Refractory headache may necessitate CSF shunting.

\section{Surgical Management}

Modern surgical management of IIH includes optic nerve sheath fenestration (ONSF) and CSF shunting. ONSF is an ophthalmic procedure where an incision is made in the optic nerve sheath, which permits CSF drainage and relieves pressure off of the optic nerves. ONSF is commonly used with acute, severe vision loss or progressive vision loss despite medical management [72-76]. At least three-quarters of children experienced resolution of optic disc edema [72, 73], and visual acuity and visual fields stabilized or improved in most patients [74]. Approximately $50 \%$ of patients with unilateral surgery experienced bilateral improvement in visual acuity, but the mechanism is unclear $[72,73,76]$. Unfortunately, initial success of surgery does not guarantee permanent visual correction. Of the 25 children cited in the literature who required ONSF, three experienced postoperative visual deterioration $[72,73,75]$.

CSF shunting is preferred for children with intractable headaches, visual loss and papilledema unresponsive to ONSF. Lumboperitoneal (LP) shunting seems to be the most successful in alleviating patient symptoms [77], with 9 of 10 children experiencing symptomatic improvement, but 7 required a total of 16 revisions as a result of shunt malfunction [78]. The procedure is associated with various complications including shunt obstruction, lumbar radiculopathy [78, 79], infection [80], and tonsillar herniation [78]. Children, may be at higher risk for developing complications, possibly secondary to increased mechanical stress (growth) or the size of the shunt tubing in the thecal sac $[78,79]$. Shunt life duration is variable and in one report, the shunts lasted only 6 months, with an average time to failure of 9-18 months [81]. LP shunting has failed to halt progressive vision loss in some cases [78]. Unfortunately, there are no reliable risk factors which predict poor shunt tolerance and the long-term visual prognosis after LP shunting. Ventriculoperitoneal shunting has been more widely used even in patients with relatively small ventricles, with the authors of one study concluding the revision rate was less compared to LP shunting [82].

ONSF is preferred when vision loss is the major issue because of its effectiveness and lower complication rate compared to shunting. 


\section{Outcome}

With prompt diagnosis and medical management, most children with mild-to-moderate disc swelling and visual field defects have complete resolution of disc swelling and visual abnormalities [4]. On average, pediatric $\mathrm{IIH}$ patients respond to treatment, with resolution of papilledema in 4.7 months [10]. Despite treatment, permanent loss of visual acuity occurs in $0-10 \%[10,18,22,26]$ and visual field loss persists in 17\% [18]. One recent report suggested that pubertal patients have a less favorable visual outcome than prepubertal, teenage, and adult patients [83].

Recurrence rate is low, between 6 and 22\% [10, 18, 22, 26]. One study's survival analysis showed that recurrences are rare during the first year, especially while on treatment [84]. In our experience, recurrences generally occur in obese adolescents who initially lose weight and subsequently regain it.

\section{Conclusions}

Much has yet to be learned about IIH etiology and pathophysiology. Larger collaborative studies need to examine the potential role of neuroendocrine and other factors in determining the relationship between age, pubertal status, and obesity in the pediatric IIH population.

\section{Medline Search Strategy}

To draft this review, 'Pediatric Idiopathic Intracranial Hypertension,' a thorough MEDLINE search of all English articles between 1992 and 2010 was conducted. Search terms include: pediatric pseudotumor cerebri, pediatric idiopathic intracranial hypertension (IIH), pediatric neoplasms, pediatric pseudotumor cerebri diagnosis, pseudotumor cerebri AND drug therapy, IIH AND drug therapy, pseudotumor cerebri AND headache, IIH AND headache, pseudotumor cerebri AND endocrine, IIH AND endocrine, pseudotumor cerebri AND acetazolamide, IIH AND acetazolamide, pseudotumor cerebri AND corticosteroids, IIH AND corticosteroids, pseudotumor cerebri AND MRI, IIH AND MRI, pseudotumor cerebri AND MRI venogram, IIH AND MRI venogram, pseudotumor cerebri AND segmental sinus stenosis, IIH AND stenosis, pseudotumor cerebri AND lumbar peritoneal shunting, IIH AND lumbar peritoneal shunting, pseudotumor cerebri AND optic nerve sheath fenestration, IIH AND optic nerve sheath fenestration, pseudotumor cerebri AND visual outcome, and IIH AND visual outcome.

In addition to searching MEDLINE, all related articles cited in reference lists of other articles were included. Non-English articles have not been included, nor have abstracts. Given that the last review was published in 1992, only a few select articles prior to 1992 have been included for historical purposes, but otherwise this review focuses mainly on articles published since 1992.

Only those articles available through the SUNY Upstate Medical University Library, University of Pennsylvania Library and Children's Hospital of Philadelphia systems (electronic or paper), without cost from journal websites, or by direct communication from the authors, were used.

\section{References}

1 Friedman DI, Jacobson DM: Diagnostic criteria for idiopathic intracranial hypertension. Neurology 2002;59:1492-1495.

-2 Durcan FJ, Corbett JJ, Wall M: The incidence of pseudotumor cerebri: population studies in iowa and louisiana. Arch Neurol 1988;45: 875-877.

3 Radhakrishnan K, Ahlskog JE, Cross SA, Kurland LT, O'Fallon WM: Idiopathic intracranial hypertension (pseudotumor cerebri). Descriptive epidemiology in Rochester, Minn, 1976 to 1990. Arch Neurol 1993;50: 78-80.

4 Babikian P, Corbett J, Bell W: Idiopathic intracranial hypertension in children: the Iowa experience. J Child Neurol 1994;9:144-149.

5 Baker RS, Baumann RJ, Buncic JR: Idiopathic intracranial hypertension (pseudotumor cerebri) in pediatric patients. Pediatr Neurol 1989;5:5-11.

6 Lessell S: Pediatric pseudotumor cerebri (idiopathic intracranial hypertension). Surv Ophthalmol 1992;37:155-166.
7 McKiernan SP, DiFazio MP: Index of suspicion. Case 3. Diagnosis: infantile pseudotumor cerebri. Pediatr Rev 2001;22:211-215.

8 Gordon K: Pediatric pseudotumor cerebri: descriptive epidemiology. Can J Neurol Sci 1997;24:219-221.

-9 Distelmaier F, Sengler U, Messing-Juenger M, Assmann B, Mayatepek E, Rosenbaum T: Pseudotumor cerebri as an important differential diagnosis of papilledema in children. Brain Dev 2006;28:190-195.

10 Cinciripini GS, Donahue S, Borchert MS: Idiopathic intracranial hypertension in prepubertal pediatric patients: characteristics, treatment, and outcome. Am J Ophthalmol 1999; 127:178-182.

11 Marshall WA, Tanner JM: Variations in pattern of pubertal changes in girls. Arch Dis Child 1969;44:291-303.

12 Marshall WA, Tanner JM: Variations in the pattern of pubertal changes in boys. Arch Dis Child 1970;45:13-23.
13 Rangwala LM, Liu GT: Pediatric idiopathic intracranial hypertension. Surv Ophthalmol 2007;52:597-617.

14 Avery RH, Shah SS, Licht DJ, Seiden JA, Huh JW, Boswinkel J, Ruppe MD, Chew A, Mistry $\mathrm{RD}$, Liu GT: Reference range of cerebrospinal fluid opening pressure in children undergoing diagnostic lumbar puncture. N Engl J Med 2010;363:891-893.

15 Rowe FJ, Sarkies NJ: The relationship between obesity and idiopathic intracranial hypertension. Int J Obes Relat Metab Disord 1999;23:54-59.

16 Scott IU, Siatkowski RM, Eneyni M, Brodsky MC, Lam BL: Idiopathic intracranial hypertension in children and adolescents. Am J Ophthalmol 1997;124:253-255.

17 Balcer LJ, Liu GT, Forman S, Pun K, Volpe NJ, Galetta SL, Maguire MG: Idiopathic intracranial hypertension: relation of age and obesity in children. Neurology 1999;52:870872. 
18 Phillips PH, Repka MX, Lambert SR: Pseudotumor cerebri in children. J AAPOS 1998; 2:33-38.

-19 Soler D, Cox T, Bullock P, Calver DM, Robinson RO: Diagnosis and management of benign intracranial hypertension. Arch Dis Child 1998;78:89-94.

20 Lim M, Kurian M, Penn A, Calver D, Lin JP: Visual failure without headache in idiopathic intracranial hypertension. Arch Dis Child 2005;90:206-210.

-21 Salman MS, Kirkham FJ, MacGregor DL: Idiopathic 'benign' intracranial hypertension: case series and review. J Child Neurol 2001; 16:465-470.

\22 Kesler A, Fattal-Valevski A: Idiopathic intracranial hypertension in the pediatric population. J Child Neurol 2002;17:745-748.

23 Weig SG: Asymptomatic idiopathic intracranial hypertension in young children. J Child Neurol 2002;17:239-241.

-24 Johnston IH, Duff J, Jacobson EE, Fagan E: Asymptomatic intracranial hypertension in disorders of CSF circulation in childhoodtreated and untreated. Pediatr Neurosurg 2001;34:63-72.

-25 Winner P, Bello L: Idiopathic intracranial hypertension in a young child without visual symptoms or signs. Headache 1996;36:574576.

-26 Youroukos S, Psychou F, Fryssiras S, Paikos P, Nicolaidou P: Idiopathic intracranial hypertension in children. J Child Neurol 2000; 15:453-457.

-27 Suzuki H, Takanashi J, Kobayashi K, Nagasawa K, Tashima K, Kohno Y: MR imaging of idiopathic intracranial hypertension. AJNR Am J Neuroradiol 2001;22:196-199.

-28 Speer C, Pearlman J, Phillips PH, Cooney M, Repka MX: Fourth cranial nerve palsy in pediatric patients with pseudotumor cerebri. Am J Ophthalmol 1999;127:236-237.

29 Capobianco DJ, Brazis PW, Cheshire WP: Idiopathic intracranial hypertension and seventh nerve palsy. Headache 1997;37:286288.

- 30 Adams C, Dean HJ, Israels SJ, Patton A, Fewer DH: Primary hypothyroidism with intracranial hypertension and pituitary hyperplasia. Pediatr Neurol 1994;10:166-168.

- 31 Krishna R, Kosmorsky GS, Wright KW: Pseudotumor cerebri sine papilledema with unilateral sixth nerve palsy. J Neuroophthalmol 1998; 18:53-55.

32 Liu GT, Volpe NJ, Galetta S: Neuro-ophthalmology: diagnosis and management. Philadelphia, Saunders, 2001.

-33 Karahalios DG, Rekate HL, Khayata MH, Apostolides PJ: Elevated intracranial venous pressure as a universal mechanism in pseudotumor cerebri of varying etiologies. Neurology 1996;46:198-202.

34 Baryshnik DB, Farb RI: Changes in the appearance of venous sinuses after treatment of disordered intracranial pressure. Neurology 2004;62:1445-1446.
35 McGonigal A, Bone I, Teasdale E: Resolution of transverse sinus stenosis in idiopathic intracranial hypertension after L-P shunt. Neurology 2004;62:514-515.

36 Higgins JN, Pickard JD: Lateral sinus stenoses in idiopathic intracranial hypertension resolving after CSF diversion. Neurology 2004;62:1907-1908.

37 Campos SP, Olitsky S: Idiopathic intracranial hypertension after L-thyroxine therapy for acquired primary hypothyroidism. Clin Pediatr (Phila) 1995;34:334-337.

38 Raghavan S, DiMartino-Nardi J, Saenger P, Linder B: Pseudotumor cerebri in an infant after L-thyroxine therapy for transient neonatal hypothyroidism. J Pediatr 1997;130: 478-480.

39 Van Dop C, Conte FA, Koch TK, Clark SJ, Wilson-Davis SL, Grumbach MM: Pseudotumor cerebri associated with initiation of levothyroxine therapy for juvenile hypothyroidism. N Engl J Med 1983;308:1076-1080.

40 Merkenschlager A, Ehrt O, Muller-Felber W, Schmidt H, Bernhard MK: Reversible benign intracranial hypertension in a child with hyperthyroidism. J Pediatr Endocrinol Metab 2008;21:1099-1101.

41 Liu GT, Kay MD, Bienfang DC, Schatz NJ Pseudotumor cerebri associated with corticosteroid withdrawal in inflammatory bowel disease. Am J Ophthalmol 1994;117:352357.

42 Levine A, Watemberg N, Hager $\mathrm{H}$, Bujanover $\mathrm{Y}$, Ballin A, Lerman-Sagie T: Benign intracranial hypertension associated with budesonide treatment in children with crohn's disease. J Child Neurol 2001;16:458461.

43 Alexandrakis G, Filatov V, Walsh T: Pseudotumor cerebri in a 12-year-old boy with Addison's disease. Am J Ophthalmol 1993;116: 650-651.

44 Condulis N, Germain G, Charest N, Levy S, Carpenter TO: Pseudotumor cerebri: a presenting manifestation of Addison's disease. Clin Pediatr (Phila) 1997;36:711-713.

45 Saenger P: Metabolic consequences of growth hormone treatment in paediatric practice. Horm Res 2000;53(suppl 1):60-69.

46 Reeves GD, Doyle DA: Growth hormone treatment and pseudotumor cerebri: coincidence or close relationship? J Pediatr Endocrinol Metab 2002;15(suppl 2):723-730.

47 Clayton PE, Cowell CT: Safety issues in children and adolescents during growth hormone therapy: a review. Growth Horm IGF Res 2000;10:306-317.

48 Malozowski S, Tanner LA, Wysowski D, Fleming GA: Growth hormone, insulin-like growth factor I, and benign intracranial hypertension. N Engl J Med 1993;329:665-666.

49 Blethen SL: Complications of growth hormone therapy in children. Curr Opin Pediatr 1995;7:466-471.
50 Koller EA, Stadel BV, Malozowski SN: Papilledema in 15 renally compromised patients treated with growth hormone. Pediatr Nephrol 1997;11:451-454.

51 Johansson JO, Larson G, Andersson M, Elmgren A, Hynsjo L, Lindahl A, Lundberg PA, Isaksson OG, Lindstedt S, Bengtsson BA: Treatment of growth hormone-deficient adults with recombinant human growth hormone increases the concentration of growth hormone in the cerebrospinal fluid and affects neurotransmitters. Neuroendocrinology 1995;61:57-66.

52 Crock PA, McKenzie JD, Nicoll AM, Howard NJ, Cutfield W, Shield LK, Byrne G: Benign intracranial hypertension and recombinant growth hormone therapy in Australia and New Zealand. Acta Paediatr 1998;87:381386.

53 Collett-Solberg PF, Liu GT, Satin-Smith M, Katz LL, Moshang T, Jr: Pseudopapilledema and congenital disc anomalies in growth hormone deficiency. J Pediatr Endocrinol Metab 1998;11:261-265.

-54 Alder JB, Fraunfelder FT, Edwards R: Levonorgestrel implants and intracranial hypertension. N Engl J Med 1995;332:1720-1721.

55 Neely DE, Plager DA, Kumar N: Desmopres$\sin ($ DDAVP)-induced pseudotumor cerebri. J Pediatr 2003;143:808.

56 Mehta V, Chapman A, McNeely PD, Walling S, Howes WJ: Latency between symptom onset and diagnosis of pediatric brain tumors: an eastern Canadian geographic study. Neurosurgery 2002;51:365-372; discussion 372363.

57 Suwanwela N, Phanthumchinda K, Kaoropthum S: Headache in brain tumor: a crosssectional study. Headache 1994;34:435-438.

58 Antunes NL: The spectrum of neurologic disease in children with systemic cancer. Pediatr Neurol 2001;25:227-235.

59 Chateil JF, Dousset V, Meyer P, Pedespan JM, San-Galli F, Rivel J, Caille JM, Diard F: Cranial aneurysmal bone cysts presenting with raised intracranial pressure: report of two cases. Neuroradiology 1997;39:490-494.

-60 Said RR, Rosman NP: A negative cranial computed tomographic scan is not adequate to support a diagnosis of pseudotumor cerebri. J Child Neurol 2004;19:609-613.

61 Ozsvath RR, Casey SO, Lustrin ES, Alberico RA, Hassankhani A, Patel M: Cerebral venography: comparison of CT and MR projection venography. Ajr 1997;169:1699-1707.

-62 Kaiser AM, Whitelaw AG: Normal cerebrospinal fluid pressure in the newborn. Neuropediatrics 1986;17:100-102.

63 Kestenbaum LA, Ebberson J, Zorc JJ, Hodinka RL, Shah SS: Defining cerebrospinal fluid white blood cell count reference values in neonates and young infants. Pediatrics; 125 : 257-264.

64 Fishman RA: Cerebrospinal Fluid in Diseases of the Nervous System, ed 2. Philadelphia, Saunders, 1992. 
65 Johnson LN, Krohel GB, Madsen RW, March GA Jr: The role of weight loss and acetazolamide in the treatment of idiopathic intracranial hypertension (pseudotumor cerebri). Ophthalmology 1998;105:2313-2317.

66 Schoeman JF: Childhood pseudotumor cerebri: clinical and intracranial pressure response to acetazolamide and furosemide treatment in a case series. J Child Neurol 1994;9:130-134.

-67 Finsterer J, Földy D, Fertl E, Rudolfstiftung $\mathrm{K}$ : Topiramate resolves headache from pseudotumor cerebri. J Pain Symptom Manage 2006;32:401-402.

- 68 Thompson PJ, Baxendale SA, Duncan JS, Sander JW: Effects of topiramate on cognitive function. J Neurol Neurosurg Psychiatry 2000;69:636-641.

-69 Liu GT, Glaser JS, Schatz NJ: High-dose methylprednisolone and acetazolamide for visual loss in pseudotumor cerebri. Am J Ophthalmol 1994;118:88-96.

70 Friedman DI, Rausch EA: Headache diagnoses in patients with treated idiopathic intracranial hypertension. Neurology 2002;58: 1551-1553.

71 Mathew NT, Ravishankar K, Sanin LC: Coexistence of migraine and idiopathic intracranial hypertension without papilledema. Neurology 1996;46:1226-1230.
72 Thuente DD, Buckley EG: Pediatric optic nerve sheath decompression. Ophthalmology 2005;112:724-727.

73 Lee AG, Patrinely JR, Edmond JC: Optic nerve sheath decompression in pediatric pseudotumor cerebri. Ophthalmic Surg Lasers 1998;29:514-517.

74 Goh KY, Schatz NJ, Glaser JS: Optic nerve sheath fenestration for pseudotumor cerebri. J Neuro-ophthalmol 1997;17:86-91.

75 Mauriello JA, Jr, Shaderowfsky P, Gizzi M, Frohman L: Management of visual loss after optic nerve sheath decompression in patients with pseudotumor cerebri. Ophthalmology 1995;102:441-445.

76 Kelman SE, Heaps R, Wolf A, Elman MJ: Optic nerve decompression surgery improves visual function in patients with pseudotumor cerebri. Neurosurgery 1992;30:391-395.

77 Rekate HL, Wallace D: Lumboperitoneal shunts in children. Pediatr Neurosurg 2003; 38:41-46.

78 Chumas PD, Kulkarni AV, Drake JM, Hoffman HJ, Humphreys RP, Rutka JT: Lumboperitoneal shunting: a retrospective study in the pediatric population. Neurosurgery 1993;32:376-383; discussion 383.
79 Eggenberger ER, Miller NR, Vitale S: Lumboperitoneal shunt for the treatment of pseudotumor cerebri. Neurology 1996;46:15241530.

80 Burgett RA, Purvin VA, Kawasaki A: Lumboperitoneal shunting for pseudotumor cerebri. Neurology 1997;49:734-739.

81 Rosenberg ML, Corbett JJ, Smith C, Goodwin J, Sergott R, Savino P, Schatz N: Cerebrospinal fluid diversion procedures in pseudotumor cerebri. Neurology 1993; 43: 1071-1072.

82 Bynke G, Zemack G, Bynke H, Romner B: Ventriculoperitoneal shunting for idiopathic intracranial hypertension. Neurology 2004; 63:1314-1316.

83 Stiebel-Kalish H, Kalish Y, Lusky M, Gaton DD, Ehrlich R, Shuper A: Puberty as a risk factor for less favorable visual outcome in idiopathic intracranial hypertension. Am J Ophthalmol 2006;142:279-283.

84 Kesler A, Hadayer A, Goldhammer Y, Almog Y, Korczyn AD: Idiopathic intracranial hypertension: risk of recurrences. Neurology 2004;63:1737-1739.

85 Smith JL: Whence pseudotumor cerebri? J Clin Neuro-ophthalmol 1985;5:55-56.

86 Friedman DI, Jacobson DM: Idiopathic intracranial hypertension. J Neuro-ophthalmol 2004;24:138-145. 